CP, 2021, Vol.10 - No20, pp. 101/117, ISSN 2014-6752. Girona (Catalunya). Universitat de Girona. DOUIEB, M.M.: La integración de las TIC en la universidad marroquí: Aproximación pedagógica. Recibido: 12/04/2021 - Aceptado: 24/07/2021

\title{
La integración de las TIC en la universidad marroquí: Aproximación pedagógica
}

\section{The integration of ICT in the Moroccan University: Pedagogical approach}

\author{
AUTOR: \\ Mohammed Mouhcine DOUIEB \\ Facultad de Letras y Ciencias Humanas- Mohammedia. \\ Universidad Hassan II. \\ Casablanca. Marruecos. \\ Mohammedmouhcine@gmail.com
}

\section{Resumen}

A causa de la situación que conoce el mundo con la pandemia del CORONAVIRUS, las universidades marroquíes han adoptado medidas ante la crisis que se relacionan con la suspensión de las clases presenciales; lo que ha dado origen a la creación de nuevas modalidades de aprendizaje mediante la utilización de plataformas y otras Tecnologías para mantener la enseñanza y con el fin de evitar la propagación del virus y mitigar su impacto. La educación a distancia ha demostrado ser una de las soluciones eficientes para satisfacer las necesidades de los estudiantes; pero las instituciones educativas en general, y las universidades en particular, se han visto obligadas a integrar las TIC en la enseñanza sin ningún estudio previo de esta integración. En el presente artículo pretendemos presentar un enfoque pedagógico de la integración de las TIC proyectando oportunidades para el aprendizaje y la innovación en la educación posterior a la pandemia.

Palabras clave: TIC; universidad; enseñanzaaprendizaje; currículum; teorías del aprendizaje. Pandemia

\section{Abstract}

Due to the situation that the world is familiar with concerning the CORONA Virus pandemic, Moroccan universities have adopted measures to face the crisis. These are related to the suspension of attendance classes; this has led to the creation of new learning modalities through the use of platforms and other Technologies to maintain teaching and in order to limit the spread of the virus and mitigate its impact. Further learning has proven to be one of the efficient solutions to meet the needs of students; But educational institutions in general, and universities in particular, have been forced to integrate ICT in teaching without any prior study of this incorporation. In this article we intend to present a pedagogical approach to the integration of ICT, projecting opportunities for learning and innovation in education after the pandemic.

Key words: ICT; university; teaching-learning; curriculum; learning theories. Pandemic. 


\section{Contextualización}

La actual situación sanitaria está modificando y va a modificar nuestras formas de vivir, de relacionarnos, de trabajar y de investigar. Por eso destacadas declaraciones de diferentes organismos internacionales se han manifestado y reiteran en distintas ocasiones la necesidad de promover la integración de las tecnologías en todos los niveles de la educación, con el objeto de poder remediar los problemas causados por la pandemia y beneficiarse de las grandes posibilidades que ofrecen estas herramientas para la vida, para los empleos tradicionales, para los trabajos que vienen apareciendo, para el ocio, para la salud, para la gobernanza, etcétera.

La universidad marroquí también está en un proceso de cambio muy importante, provocado por la pandemia del CORONAVIRUS y la necesidad de adoptar una nueva modalidad de enseñanza que combina lo presencial y lo virtual. Lo que implica, tanto para el profesor como para el alumno, adquirir nuevos conocimientos técnicos, pero también pedagógicos, y lo que supone también una nueva concepción del trabajo de ambos donde tienen que buscar nuevas estrategias y modificar la forma tradicional de entender la docencia.

La nueva realidad ha abierto el debate sobre la necesidad de un cambio en las formas de enseñar y aprender, un cambio que busque nuevos métodos fundamentados en la idea del estímulo continuo. Las personas, que quieren aprender en cualquier momento de su vida, tendrán que encontrar una respuesta personalizada a sus necesidades, una respuesta que compense adecuadamente su esfuerzo. Esto significa una transformación en las metodologías utilizadas tradicionalmente en las escuelas.

En el modelo predominante hasta ahora en las universidades marroquíes, el docente es la fuente de información más importante y su labor gira en torno al discurso oral. Desde nuestro punto de vista se plantean nuevas funciones docentes, entre ellas la de buscar, seleccionar y organizar el conjunto de tareas que habrá de proponer al alumno, así como ofrecer y guiar en el uso de materiales y recursos necesarios para hacerlo. Cada alumno debe construir su propio conocimiento elaborando la información que recibe. Los cambios, que deberán llevarse a cabo en cuanto a la docencia, solicitarán una participación activa del profesor y la utilización de nuevos recursos y estrategias para adaptarse a este cambio.

Ante esta realidad, se hace necesario avanzar hacia la alfabetización digital, proporcionando herramientas y recursos para poner la formación básica en TIC al alcance de todos, teniendo en cuenta dos perspectivas de las tecnologías: como herramientas que facilitan la realización de una gran diversidad de tareas, y como instrumentos que favorecen la formación permanente a lo largo de toda la vida.

Las personas, y especialmente los estudiantes, deberán ser capaces de utilizar las herramientas para producir, presentar y comprender información compleja y tener la habilidad necesaria para acceder a servicios basados en Internet, buscarlos y utilizarlos, pero también desarrollar una actitud crítica y reflexiva respecto a la información disponible y un uso responsable de los medios interactivos.

La importancia de todas estas habilidades reside no sólo en la utilización de los recursos, sino, fundamentalmente, en qué se puede hacer con ellos. Aquí es donde juega un papel importante el profesor que deberá proponer unas actividades de aprendizaje que favorecen la construcción del conocimiento de sus alumnos utilizando estas tecnologías que, a su vez, les ayudan a ser creativos, innovadores y, todo ello, con espíritu crítico. 
Pero para lograrlo también es necesario que el profesor esté preparado. El problema que puede surgir radica en la formación de los profesores actuales, mayoritariamente inmigrantes digitales (Alejandro Piscitelli, 2006) que no siempre tienen suficiente conocimiento de las TIC. El logro de esta competencia en un grado satisfactorio sólo se dará cuando realmente se utilicen estas tecnologías en propuestas de aprendizaje que supongan un uso avanzado, de manera que los alumnos aprendan a utilizarlas y, a la vez, les permita avanzar en el conocimiento de otros conceptos relacionados con áreas curriculares diferentes.

Las primeras experiencias de la integración de las TIC en la enseñanza superior fomentan la idea de que debe hacer de forma planeada, e involucrando a toda la organización. Así, las TIC podrán convertirse en un factor transformador e innovador de la universidad.

En tiempos de pandemia del coronavirus y tras el estado de emergencia sanitaria declarado por el Reino de Marruecos, el Ministerio de Educación Nacional, Formación Profesional, Educación Superior e Investigación Científica ha tomado importantes medidas preventivas para garantizar la continuidad pedagógica del año 2019/2020 y ha decidido la suspensión de las clases presenciales en las escuelas y universidades de los sectores público y privado. El objetivo era luchar contra la propagación de la pandemia desde el 16 de marzo de 2020 hasta el 20 de mayo de 2020. Esta decisión, tomada a tiempo, según algunos expertos en el campo de la educación, fue ampliamente aplaudida por los diversos actores de la sociedad marroquí. Las clases presenciales han sido sustituidas por la enseñanza a distancia. Ante esta situación de crisis, surgen interrogantes:

- ¿Se ha preparado a los profesores y alumnos para afrontar esta situación impredecible?

- ¿Se ha capacitado a las instituciones públicas en la enseñanza a distancia?

- ¿Qué medios se han puesto a su disposición para resolver este problema?

- ¿Se ha superado la brecha digital?

En este trabajo intentaremos aportar respuestas a estas preguntas con el fin de proponer soluciones de acuerdo con las necesidades y exigencias de los alumnos y loEs requerimientos de la situación actual desde una perspectiva pedagógica.

\section{El impacto de la pandemia sobre el transcurso de la enseñanza}

Con el fin de medir el impacto de la pandemia sobre el transcurso de las enseñanzas en las universidades marroquíes, un equipo compuesto por profesores-investigadores lanzó dos encuestas paralelas durante el período de confinamiento, una de las cuales alcanzó a 200 profesores y la otra afectó a 1340 estudiantes de las universidades públicas (Benkaraache et al., 2020). El método elegido para recoger las respuestas es la consulta en línea a través de Internet, dadas las condiciones atípicas de confinamiento, que excluyen el uso de cualquier otro método. Los resultados de la encuesta a los docentes revelaron que el 65,5\% está satisfecho en general con su educación a distancia durante el periodo de confinamiento y que casi el $60 \%$ ha sido capaz de adaptarse a esta nueva modalidad de enseñanza.

En cuanto a las plataformas y los recursos digitales utilizados durante el periodo de confinamiento, los documentos PDF, PPT o Word son los más utilizados con un porcentaje del $76 \%$ seguidos de los cursos interactivos a través de plataformas de internet con un porcentaje del $70 \%$. Cabe destacar que más de la mitad de los docentes que respondieron $(56,5 \%)$ ha sido entrenado en una herramienta o plataforma de aprendizaje a distancia anteriormente. 
El 61,5\% de los docentes encuestados dice que la enseñanza a distancia no puede sustituir a la enseñanza presencial. Múltiples obstáculos fueron mencionados por los encuestados como el problema de la conexión en un $78 \%$, seguido de la falta de coordinación y las modalidades compartidas y comunes a todos los docentes durante el periodo de confinamiento. Sin embargo, el 64,5\% de los docentes condicionó el éxito de esta innovadora forma de educación a la eficiencia del sistema adoptado por las escuelas. En general, el $65 \%$ cree que la educación a distancia no aportará un valor añadido a la educación superior.

Los resultados de la encuesta a los estudiantes muestran que la mayoría no está muy satisfecha con esta experiencia (79,4\%). El 56\% dijo no haber sido capaz de adaptarse a esta nueva forma de enseñanza, mientras que el 33\% todavía está en proceso de adaptación incluso después de varios meses de aprendizaje a distancia. El problema de la conexión a Internet y la dificultad de realizar ejercicios de aplicación bajo la supervisión del profesor fueron los dos primeros problemas encontrados en la experiencia de la enseñanza a distancia.

El uso de clases interactivas a través de plataformas de internet ha sido masivo al ritmo del $61 \%$, sin embargo, solo el $44,5 \%$ de los estudiantes aprecia esta modalidad de enseñanza. La clase grabada es la técnica más apreciada por los alumnos al ritmo del 51,3\%. Los soportes clásicos, a saber, las presentaciones PPT y los documentos PDF, son muy poco apreciados por los estudiantes encuestados. El $41,3 \%$ de las clases fueron monitoreadas con un smartphone y el $37,2 \%$ con un ordenador personal o Tablet. El 42\% de los estudiantes encuestados está convencido de que la enseñanza a distancia no podrá sustituir a las clases presenciales, mientras que el 29,2\% no está convencido del valor añadido de esta nueva forma de enseñanza. Así, el $57 \%$ no desea seguir clases a distancia en el futuro.

Creemos que la educación presencial y a distancia son complementarias y serán muy útiles cuando se desplieguen en una secuencia bien estudiada. Las condiciones excepcionales de la pandemia han hecho que se integren las TIC en la enseñanza sin ningún estudio previo. Otro elemento importante que obstaculizó dicha operación son las disparidades en cuanto al acceso a Internet, teléfonos y ordenadores.

\section{La Universidad marroquí y las TIC}

En los últimos años, el gobierno marroquí ha hecho esfuerzos considerables para mejorar las escuelas y las universidades. En 2009 se lanzó, bajo la presidencia del Rey Mohamed VI, una Estrategia Nacional llamada "Marruecos numérico 2013". Esta estrategia tenía como objetivo hacer de las TIC un vector del desarrollo humano y una fuente de productividad y de valor añadido para otros sectores económicos y para la Administración Pública. Se pretendía situar a Marruecos como un eje tecnológico regional y aumentar el número de empleos al 58000 en 2013.

Por otra parte, el Ministerio de Educación Nacional ha introducido la enseñanza de las TIC en beneficio de los estudiantes universitarios (módulo TIC para estudiantes en el semestre 5) y de los profesores en prácticas en los centros regionales de formación y educación (CRMEF). Una gran proporción de los maestros de escuela se han beneficiado de la formación continua impartida como parte de la estrategia del programa GENIE' (Generalización de las tecnologías de la información y la comunicación en la educación en Marruecos) y por el Centro de Formación Marroquí-Coreano (CMCF). 
Los principales objetivos fijados por la estrategia GENIE son:

- implicar activamente a los docentes en la integración de las TIC en la educación

- contribuir a mejorar la calidad de la enseñanza y el aprendizaje mediante la explotación de las TIC

Algunos profesores no se beneficiaron de estas formaciones porque no eran obligatorias. Sin embargo, muchos otros, deseosos de innovar, han manifestado su interés en seguir este tipo de formación. A este respecto, el ministerio responsable organizó concursos para fomentar proyectos en torno a las TIC y otorgar premios a profesores innovadores.

Otra iniciativa tomada por el gobierno marroquí es la creación, el14 de septiembre de 2017, de la Agencia de Desarrollo Digital (ADD)²; una institución pública estratégica con personalidad jurídica y autonomía financiera. Bajo la supervisión del Ministerio de Industria, Comercio y Economía Verde y Digital (MICEVN), la Agencia es responsable de implementar la estrategia de desarrollo digital del Estado, que incluye la universidad, y promover la difusión de las herramientas digitales y el desarrollo de su uso entre los ciudadanos. Su objetivo primordial es reducir la brecha digital, apoyar la revolución de la Industria 4.0 y liderar la gestión del cambio de la sociedad a través de la formación y la sensibilización. Es responsable, entre otras cosas, de fomentar la investigación, el desarrollo, la innovación social y empresarial y garantizar una inclusión digital responsable y sostenible. En la enseñanza superior, cada universidad se ha dotado de su propia plataforma del e-learning. Los estudiantes, gracias a su cuenta institucional, pueden acceder a estas plataformas para el intercambio de información y de los documentos. La mayoría de los profesores tienen sus espacios en este tipo de plataformas donde pueden dar sus clases en línea. Si tomamos el ejemplo de la Universidad de Hassan II de Casablanca, los profesores tienen la posibilidad de grabar sus cursos en forma de MOOC (Massives open on line courses), o CLOM (Massive and open online courses).

En el marco del Plan de Acción 2018-2028, la Fundación Mohammed VI de Promoción de las Obras Sociales de la Educación-Formación ${ }^{3}$ lanzó en junio de 2021 el programa "Nafida" para promover el acceso a las TIC destinado a estudiantes y profesores del sector público. El programa consiste en la concesión de una subvención individual de hasta 2000 dirhams (200 euros) al adquirir un ordenador y un descuento del $25 \%$ en las tarifas de suscripción pública para la conexión a Internet de banda ancha (4G y fibra óptica).

De modo general podemos decir que Marruecos es consciente de la importancia de la introducción de las TIC en todos los ámbitos y de la necesidad de preparar al país para competir en un mundo cada vez más globalizado, que incorpora rápidamente los beneficios de las TIC y las reconoce como una herramienta clave para incrementar los niveles de desarrollo económico y social.

\section{La brecha digital}

la Organización de las Naciones Unidas para la Educación, la Ciencia y la Cultura (UNESCO) señala que 826 millones de alumnos y alumnados, mantenidos fuera de las aulas por la pandemia del Covid-19, no tienen acceso a un ordenador en casa y 706 millones no tienen Internet en casa, mientras que la educación digital a distancia se utiliza para garantizar la continuidad de la educación en la gran mayoría 
de los países. Según una nota de NOTICIAS ONU, las disparidades son particularmente marcadas en los países de bajos ingresos, particularmente en África, donde el $89 \%$ de los estudiantes no tienen acceso a ordenadores y el $82 \%$ no tienen Internet. Además, alrededor de 56 millones de profesores viven en lugares no atendidos por redes móviles, casi la mitad de ellos en África subsahariana.

Según revela un informe de la firma consultora Oxford Business Group ${ }^{4}$, el sector de las TIC en Marruecos es uno de los más desarrollados del continente africano y ha crecido significativamente desde el inicio de la liberalización en los años noventa.

La mejora del acceso a Internet es uno de los principales objetivos del Plan Digital 2020 de Marruecos, pero se siguen notando disparidades entre el mundo urbano y el mundo rural en cuanto al acceso a las TIC (Gráfico 1).

\section{Gráfico 1: Equipamiento de los hogares en Ordenadores y Tablet $^{5}$}

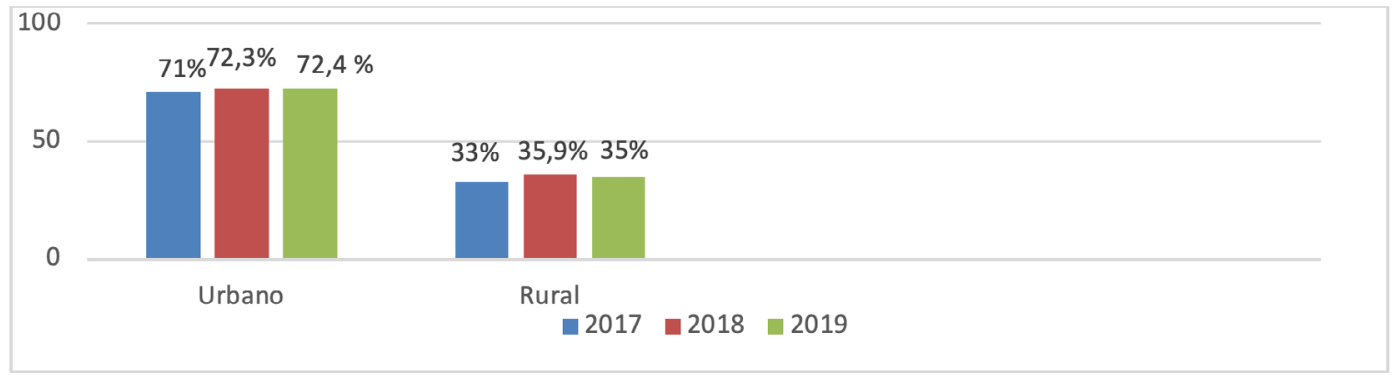

La brecha digital está presente no sólo en el lado de los estudiantes del mundo rural que no tienen los medios para adquirir un teléfono inteligente, ordenadores o conexión a Internet, sino también en el lado de algunos profesores que desafortunadamente no integran regularmente las TIC en sus prácticas de enseñanza.

Otro dato que nos parece pertinente es el equipamiento en material adecuado para un aprendizaje a distancia. Según las últimas cifras de una encuesta de la Agencia Nacional de Reglamentación de Telecomunicaciones ${ }^{6}$ (ANRT), refiriéndose al ámbito educativo, el $45 \%$ de los estudiantes universitarios no dispone de ordenador o otro material para su aprendizaje (Grafico 2). 


\section{Gráfico 2: Equipamiento en Ordenadores y Tablets en el ámbito escolar ${ }^{7}$}

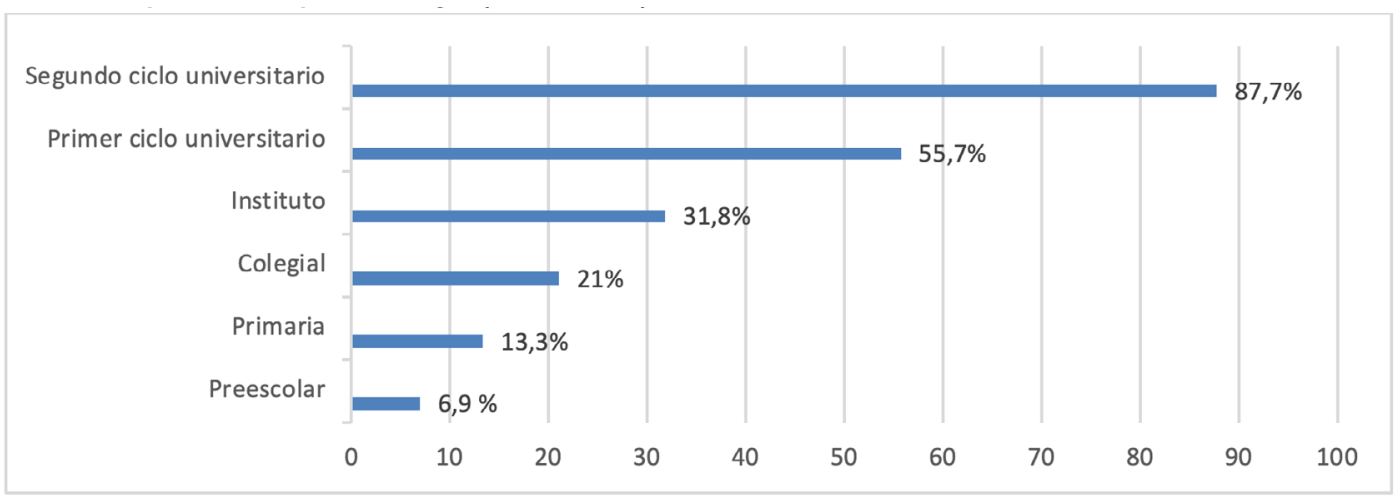

El acceso a internet es otro elemento que ha influido mucho en el éxito de la enseñanza a distancia. Según las cifras de la ANRT, Marruecos ha conocido una gran evolución en cuanto al acceso a Internet (Gráfico 3), aunque las disparidades siguen existiendo entre el mundo urbano y el mundo rural.

\section{Gráfico 3: Porcentaje de equipamiento en Internet en los hogares de 2010 a $2019^{8}$}

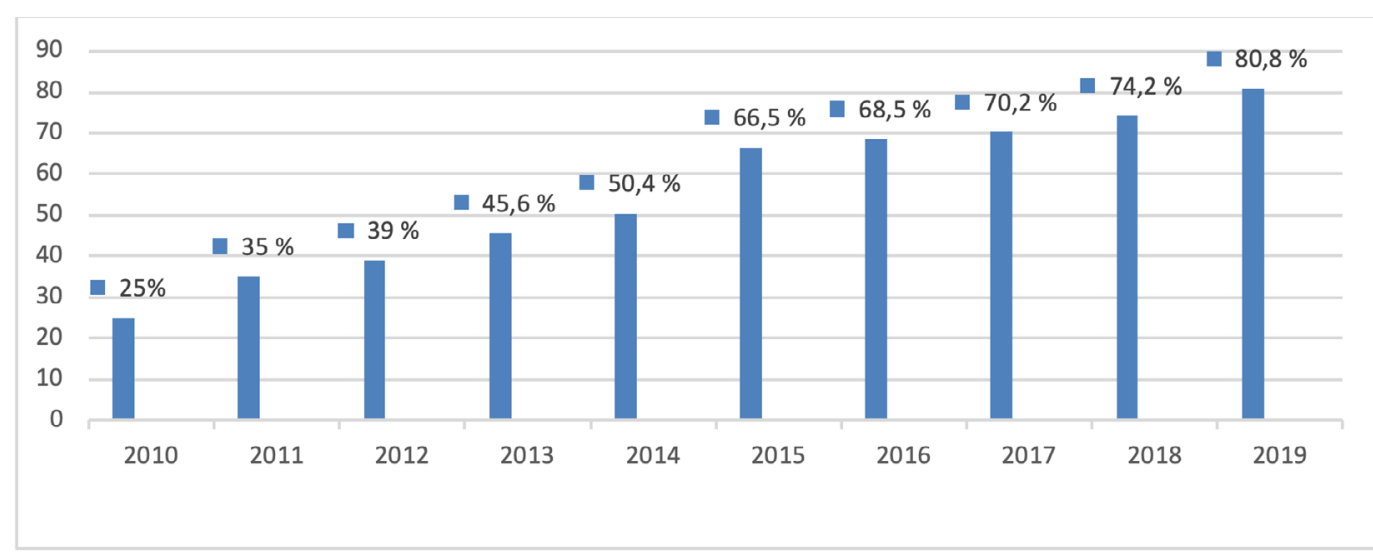

Pero, paradójicamente, esta evolución no ha tenido repercusiones positivas en el mundo educativo. En nuestra opinión, este hecho se debe a que la mayoría de los usuarios utiliza Internet con sus teléfonos móviles para la comunicación (chat, redes sociales, whatsApp, etc.) o para la diversión y no para los estudios.

Cabe recordar que el Ministerio, para remediar este problema, ha puesto a disposición canales de televisión pública para la difusión de las clases y para llegar a una gran proporción de estudiantes de las zonas rurales. 
En resumen, existe una enorme distancia entre las expectativas y los hechos en lo que concierne al impacto de las TIC en la educación en todos los niveles. Esta distancia no puede atribuirse únicamente a los problemas de acceso. Incluso con acceso pleno, su uso es por lo general limitado y poco innovador. Los distintos actores de la educación en Marruecos han realizado un gran esfuerzo para superar esta crisis. A través de las distintas redes sociales, hemos observado varias iniciativas con el objetivo de ayudar a los estudiantes a beneficiarse de la educación a distancia. Estos últimos, por su parte y a pesar de las dificultades, han demostrado estar implicados en este nuevo modo de enseñanza/aprendizaje.

Pensamos que la incorporación de las TIC no genera automáticamente dinámicas de mejora de la enseñanza y del aprendizaje. Sin embargo, la necesidad de disponer de la infraestructura y el equipamiento es primordial, aunque es necesario completar esta inversión en la formación de los profesores y concretamente en los usos.

En el caso de la universidad marroquí, las TIC no han tenido una influencia positiva en el rendimiento en este periodo de la pandemia, porque se han incorporado sin una planificación previa. Por eso pensamos que, para integrar las TIC en la universidad, hay que tener en cuenta criterios fundamentales en el diseño de políticas orientadas a su incorporación a la enseñanza formal. La formación del profesor constituye un elemento esencial, debe centrarse en los usos de las TIC más que en sus características y potencialidades técnicas. Es primordial poner a disposición del profesor recursos y apoyos que contemplen tanto los aspectos técnicos como los aspectos psicopedagógicos y didácticos. También es importante primar los usos transformadores e innovadores de las TIC, los que posibilitan nuevas formas de aprender y enseñar. Al final, hay que plantear la incorporación de las TIC en la universidad marroquí no como un fin en sí mismo; sino en el marco de una dinámica de innovación y mejora educativa.

En lo que sigue intentaremos presentar un modelo de integración de las TIC en la enseñanza superior en Marruecos desde una perspectiva pedagógica.

Si queremos entender el uso de las TIC como medio y recurso didáctico, no puede ser desde una perspectiva aislada del currículum. Por lo tanto, las TIC deben ser concebidas como un elemento integrado en el currículum y estrechamente ligadas a su diseño y su desarrollo.

\section{La integración curricular de las TIC}

Integrar las TIC es más complejo que integrar otros recursos. Afecta a la organización de la totalidad de la institución educativa en cuestión porque implica aspectos como las Infraestructuras: equipos informáticos, espacios, instalaciones eléctricas, redes, la formación y actitudes del profesor y el proyecto educativo y curricular. Es, entonces, necesario tener en cuenta el concepto de integración curricular para ver sus implicaciones, así como deducir sus modelos.

Una primera aproximación se basa en la distinción entre el uso curricular y la integración de las TIC en el currículum. Según Gutiérrez Martín, usar curricularmente las tecnologías puede implicar utilizarlas para los más diversos fines, sin un propósito claro de apoyar el aprendizaje de un contenido (Alfonso Gutiérrez Martín, 2007). Por el contrario, la integración curricular de las TIC implica su uso para conseguir un propósito de aprender un concepto o un proceso en una disciplina curricular específica. Se trata de valorar las posibilidades didácticas de las TIC en relación con los objetivos y los fines educativos. 
Por otra parte, Cristian Cerda afirma que la integración curricular implica una combinación de las TIC y los procedimientos tradicionales de enseñanza para producir aprendizaje (Cristian Cerda, 2002, p179.) de tal forma que no se prevé una reformulación del proceso de enseñanza a través de las TIC, sino que éstas se convierten en un elemento integrado en el sistema ya existente, de tal forma que faciliten y mejoren el aprendizaje.

Otra perspectiva a tener en cuenta es la de Begoña Gros, que habla de la integración curricular de las TIC como un elemento invisible que mejora la enseñanza-aprendizaje de forma imperceptible (Begoña Gros, 2000, p143). En este caso, se hace referencia directa al uso de los ordenadores. Realiza una distinción que ayuda a aclarar su visión: los ordenadores en el aula y el aula de los ordenadores, dando como modelo la primera opción que debe ser planteada no sólo desde el punto de vista de las instalaciones, sino también curricular.

En esta misma línea, E Diezmas, E. N. M., \& Graells, P. M. (2016), plantean que "...el impacto de las tecnologías en la educación no se limita a proporcionar instrumentos para la mejora didáctica. La tecnología puede constituir en sí misma un elemento que desencadene y genere un cambio de los esquemas tradicionales por el que se viene abogando desde hace prácticamente un siglo....'

Según Julio Cabero (Julio Cabero, 2001, p308) antes de llevar a cabo cualquier tipo de integración curricular de las TIC, se han de comprender una serie de hechos. Cualquier tipo de medio, independientemente de su grado de complejidad, es siempre un recurso didáctico, que debe estar relacionado con los objetivos, contenidos y características de los alumnos para que adquieran una validez didáctica. El aprendizaje no se basa en el medio, sino en las estrategias y técnicas didácticas que se apliquen sobre el mismo.

El profesor es el elemento más significativo para determinar el uso de un medio en un contexto educativo, dado que es el agente que más lo conoce y podrá determinar sus posibilidades en las actividades con los alumnos.

Para los docentes la integración curricular demanda niveles superiores de aprendizaje puesto que fomenta la indagación, reflexión y experiencia, por lo que las actividades deberán estar orientadas a desarrollar las potencialidades de los estudiantes. Esto, con el propósito de romper paradigmas de la educación tradicional, donde el docente era la única fuente del conocimiento. (Barreto y Iriarte 2017, 20)

Antes de pensar en qué medio se utilizará, será necesario determinar para quién es utilizado, cómo y qué pretendemos con este uso. Hay, entonces, una serie de elementos contextuales que determinarán tanto la elección como el uso que podremos dar a los medios: los espacios disponibles, las instalaciones, los aspectos económicos, sus destinatarios y los elementos que provocan una mayor necesidad de planificación incluso anterior a su integración en el currículum.

Debido a sus sistemas simbólicos y sus formas de estructuración, los medios determinan diversos efectos cognitivos en sus receptores, de tal forma que se propicia el desarrollo de determinadas habilidades cognitivas. El alumno no debe ser un receptor pasivo de la información; debe ser considerado, desde la planificación curricular, como un elemento activo en el uso de los medios que puede utilizar de forma expresiva, permitiéndole generar, tratar y representar información o conocimientos. 
La aplicación directa de los medios no provoca un cambio educativo por sí sola, porque el hecho de incluirlos en la práctica educativa sin ningún tipo de planificación no hace que se conviertan por sí mismos en una innovación. Debe quedar claro que no existe lo que se podría llamar un «supermedio», porque no existen unos medios mejores que los demás, sino más adecuados en función de una serie de objetivos que se persigan, así como de las elecciones metodológicas que hagamos.

Así que es imposible llevar a cabo una integración curricular de las TIC sin contar con el apoyo institucional, tanto desde el punto de vista administrativo a partir del uso de las TIC en tareas administrativas como por los presupuestos para la adquisición de tecnología. Los recursos tecnológicos de los que dispone la institución son básicos para la previsión de su uso en el currículum. Dependiendo de las posibilidades del centro en infraestructuras, se podrá llevar a cabo un mayor o menor grado de integración curricular. Los recursos de hardware y conectividad a la red son básicos para esta tarea.

Podemos afirmar, entonces, que, si se opta por un modelo de enseñanza que apueste plenamente por la integración curricular de las TIC en la universidad marroquí, habrá que tener en cuenta que es un proceso complejo que debe empezar a llevarse a cabo incluso antes de iniciar la programación del currículum. Además, un conocimiento del contexto que rodea la integración curricular de las TIC resulta básico para que se produzca en función de las propias características de la institución y determinar, así, el modelo de integración de las TIC.

\subsection{Modelos de integración de las TIC}

Si los medios están ligados a la visión educativa en la que se enmarcan, habrá que determinar qué uso y grado de integración curricular se contempla a partir del modelo formativo que se considere. Julio Cabero (Julio Cabero, 2001, p314) plantea la existencia de tres modelos o perspectivas básicas:

- La perspectiva técnica: Desde esta perspectiva el profesor es un simple usuario, el alumno receptor pasivo y los medios son producidos por expertos ajenos al contexto escolar que los presentan como elementos neutros. Esta perspectiva obedece a percepciones más tradicionales del currículum, en las que el alumno es un receptor pasivo de la información en función del modelo positivista. El papel del profesor es el de transmitir las orientaciones de la Administración a través del medio. Desde esta perspectiva, tal y como señala Begoña Gros, "el papel principal de las TIC es el de transmitir la información".(Begoña Gros, 2000, p128)

- La perspectiva práctica: Desde esta perspectiva, basada en la interpretación del contexto social, el conocimiento no se descubre, sino que se genera a partir de las interacciones humanas. En este caso, como afirma Begoña Gros, "el uso de las TIC iría precedido de un análisis y comprensión de los significados construidos por los propios conocimientos de profesores y alumnos" (Begoña Gros, 2000, p129), de tal forma que el planteamiento curricular se basaría mucho más en actividades de tipo expresivo basadas en el uso de herramientas como manera de fomentar la creatividad. En esta perspectiva, los medios se consideran como elementos investigadores que realizan diversas funciones colaborativas, los profesores y los alumnos como diseñadores de medios y la elaboración de materiales se concibe como un trabajo.

- La perspectiva crítica: Esta perspectiva fomenta el uso de aquellas TIC que faciliten el análisis de los contenidos de los discursos emitidos por diferentes medios de comunicación. Se usan como medio de análisis del entorno psicosocial del acto educativo, desde una perspectiva democrática que permite el uso funcional de la tecnología y el mismo grado de acceso al conocimiento para profesores y alumnos. Las TIC son, entonces, elementos para el análisis de la realidad psicosocial, 
para la transformación de la práctica evaluativa y son funciones para la liberación, la democratización y la emancipación. Aunque las perspectivas curriculares determinan el uso de las TIC, hay que tener en cuenta un nivel más concreto en el que se manifiestan diversos modelos de integración curricular de las tecnologías, en relación con las otras materias y con el propio aprendizaje del alumno.

En el caso de la universidad marroquí, consideramos que la integración de las TIC debe adoptar una perspectiva práctica que fomenta la productividad y la generación del conocimiento y donde las herramientas tecnológicas son elementos de investigación que permiten, por una parte, al alumno desarrollar su autonomía en el aprendizaje y, por otra, al profesor desempeñar su papel de guía y orientador.

\subsection{Las TIC y las teorías del aprendizaje}

Las actividades de enseñanza, instrucción, formación, o en general la transmisión del conocimiento, están asociadas a diferentes perspectivas sobre el aprendizaje, y éstas evolucionaron con el tiempo, en sus fundamentos, en sus propósitos y toman forma en el acto de aprender. Las TIC han sido aplicadas y se aplican a modelos pedagógicos diferentes. Por tanto, si bien es cierto que la tecnología no es neutra, también su utilización no hace cambiar de manera automática un modelo que se basa en una concepción determinada del aprendizaje.

Un análisis de las diferentes perspectivas de la educación sería incompleto sin hacer referencia a los que tradicionalmente se consideraban los tres principales enfoques teóricos, es decir, el conductismo, el cognitivismo y el constructivismo.

A continuación, presentaremos un panorama de las diferentes teorías del aprendizaje en relación con las TIC para averiguar cuál de ellas es la más adecuada para un modelo de aprendizaje basado en las TIC en la universidad marroquí.

\subsubsection{El conductismo y las TIC}

Para Peggy Ertmer y Timothy Newby, el aprendizaje conductual se muestra como cambio de un comportamiento particular (Peggy Ertmer y Timothy Newby, 1993, p.16). Estos autores consideran que el profesor juega principalmente el papel de la organización de las contingencias externas, tales como el establecimiento de objetivos, la indicación de pistas o indicios que guían la conducta del alumno, y también la organización de los refuerzos que deben seguir las respuestas dadas por los alumnos.

El conductismo se basa en la repetición de diferentes acciones para lograr el aprendizaje requerido en respuesta a las mismas acciones (Torrenteras, 2015). Es un enfoque basado en la elaboración de unidades de contenido que disponen de ejercicios muy estructurados, que siguen una pauta de dificultad creciente y que da al alumno la posibilidad de avanzar si lo realiza correctamente o de volver a hacer los ejercicios de nivel inferior si no logra el resultado correcto.

Los tutoriales y otras formas de enseñanza asistida por ordenador (EAO) son un claro ejemplo de la aplicación del enfoque conductista al uso de las TIC en la enseñanza, y las disciplinas consideradas ciencias exactas es el campo más habitual de aplicación. 


\subsubsection{El cognitivismo y las TIC}

El cognitivismo considera la experiencia del estudiantado y su desarrollo cognitivo; a diferencia del conductismo, sí importan los pensamientos y sentimientos (Delgado y Alvarado, 2016).

El aprendizaje o la construcción del conocimiento en el cognitivismo son algo diferente de la transmisión directa a los alumnos. El aprendizaje, pues, es un proceso en que la persona interactúa con el mundo para construir, comprobar y refinar su propia representación cognitiva del mundo.

Para Peggy Ertmer y Timothy Newby, el aprendizaje cognitivo es, precisamente, el cambio en el conocimiento almacenado en la memoria a largo plazo, y el proceso del aprendizaje tiene lugar en la ejecución de pasos de la recepción de los estímulos, su codificación y su posterior almacenamiento y organización. (Peggy Ertmer y Timothy Newby, 1993. P 18). El profesor es responsable y capaz de proporcionar apoyo para el almacenamiento de la información y la organización de la nueva información y hacer conexiones entre la nueva información y el conocimiento existente, lo cual se llama proceso de ayuda, atención, codificación y recuperación de los conocimientos almacenados.

En este contexto, las TIC son herramientas que deben permitir el desarrollo de entornos educativos en los que los alumnos construyen su propio conocimiento mediante la interacción con sus elementos.

Un ejemplo que puede ilustrar el uso de las TIC desde este enfoque es el uso de la web y los productos hipermedia para desarrollar lo que se conoce como formación basada en proyectos, aprendizaje por descubrimiento, exploración guiada, simulaciones o formación basada en recursos.

\subsubsection{El constructivismo y las TIC}

Las contribuciones de Vygotsky (Lev Semiónovich Vygotsky, 1981) y Ausubel (David Ausbel, 1983) a las Teorías del Aprendizaje, les aportan un enfoque social. Los aspectos sociales y culturales del contexto condicionan el aprendizaje y proporcionan al alumno herramientas potenciales para ir construyendo un nuevo conocimiento.

El constructivismo tiene como principal objetivo que el alumno aprenda de manera funcional. Así, se exige a los alumnos un aprendizaje real basado en la creación de modelos mentales y en la resolución de problemas reales, fomentando la argumentación y el espíritu crítico a la hora que provoca la autonomía moral e intelectual del alumno.

En la teoría constructivista, el aprendizaje se basa en la experiencia de enseñanza del alumnado, donde el conocimiento nuevo se une al ya adquirido, para así generar la creación de lo aprendido mediante nuevas experiencias (Fernández, 2016).

El profesor es considerado como un mediador entre el conocimiento y el aprendizaje del estudiante, comparte sus experiencias y sus saberes en una actividad conjunta de construcción del conocimiento. Por tanto, el profesor acompaña al alumno en todo su proceso de formación, siendo, durante este proceso, una persona reflexiva que piense de manera crítica sobre su trabajo, capaz de tomar decisiones y solucionar los problemas que se le presenten de la mejor manera y tomando en cuenta el contexto sociocultural del contexto donde se encuentre. Además, el profesor debe promover los aprendizajes significativos, que tengan sentido y que sean realmente útiles y aplicables en la vida cotidiana del estudiante. 
Para Peggy Ertmer y Timothy Newby ( Peggy Ertmer y Timothy Newby, 1993, p 23), el aprendizaje en una perspectiva constructivista es el cambio del significado construido por la experiencia y la resolución de problemas mediante el trabajo colaborativo. Desde esta perspectiva del aprendizaje, el profesor es responsable de dar forma y guiar el proceso de construcción del conocimiento, poniendo los problemas idóneos y la creación de actividades de aprendizaje en grupo. El estudiante es quien crea el significado, a la vez que los objetivos de aprendizaje no están predeterminados, ni tampoco se prediseña la instrucción. (Martin et al. 2017, p. 54)

Las TIC en el aprendizaje constructivista pueden apoyar el aprendizaje mediante el uso de los ordenadores ofreciendo un medio creativo para que los alumnos se expresen y demuestren que han adquirido nuevos conocimientos. Los proyectos de colaboración en línea y las publicaciones en la web también han mostrado una gran eficacia para que los profesores impliquen a sus alumnos en el proceso de aprendizaje.

En esta breve síntesis, podemos observar que podemos enfocar el uso de las TIC de manera bastante diversa, tal como representa la tabla de Begoña Gros (Begoña Gros, 2000, p 71)

\begin{tabular}{|l|l|l|}
\hline TIPOS DE PROGRAMAS & TEORÍAS DEL APRENDIZAJE & MODELOS INSTRUCTIVOS \\
\hline $\begin{array}{l}\text { Enseñanza asistida por } \\
\text { ordenador (primeros } \\
\text { programas) }\end{array}$ & Conductismo & $\begin{array}{l}\text { Aprendizaje basado en la } \\
\text { enseñanza programada }\end{array}$ \\
\hline $\begin{array}{l}\text { Programas multimedia de } \\
\text { enseñanza, simulaciones } \\
\text { Hipertextos }\end{array}$ & Cognitivismo & $\begin{array}{l}\text { Aprendizaje basado en } \\
\text { el almacenamiento y } \\
\text { la representación de la } \\
\text { información }\end{array}$ \\
\hline LOGO, micromundos & Constructivismo & $\begin{array}{l}\text { Aprendizaje basado en el } \\
\text { descubrimiento }\end{array}$ \\
\hline $\begin{array}{l}\text { Programas de comunicación } \\
\text { ingán }\end{array}$ & Teorías sociales del aprendizaje & Aprendizaje colaborativo \\
\hline
\end{tabular}

Tabla: Begoña Gros

A partir de lo visto anteriormente, podemos afirmar que las TIC reafirman la teoría constructivista sobre el aprendizaje que cree en la capacidad y necesidad de que el alumno sea el constructor de su conocimiento. En este sentido, las TIC pasan a ser una herramienta básica, un pilar central en este proceso de aprendizaje. El alumno tiene en el ordenador la posibilidad de buscar información, interactuar con alumnos y profesores, expresar sus opiniones a un público mucho más amplio y, en definitiva, interactuar y comunicarse en cualquier momento y lugar.

El constructivismo fomenta la interacción directa entre el alumno y el profesor. Éste no adopta una posición de superioridad, sino que se pone al nivel del alumno y lo guía en el aprendizaje. Para el constructivismo, el contexto social influye sobre el aprendizaje y las relaciones sociales y el entorno del alumno condicionan la construcción del conocimiento. 


\subsubsection{El Conectivismo: Una nueva perspectiva en el aprendizaje mediante las TIC}

Después de haber abordado las que se consideran principales perspectivas de aprendizaje, dirigimos nuestra atención a la aparición de una nueva perspectiva en el aprendizaje llamada "Conectivismo" (George Siemens, 2005) que ha sido desarrollada por George Siemens. Según este autor:

El conectivismo es la integración de los principios explorados por las teorías del caos, redes, complejidad y auto-organización. El aprendizaje es un proceso que ocurre en el interior de ambientes difusos de elementos centrales cambiantes que no están por completo bajo el control del individuo, pero también un proceso que puede residir fuera de nosotros, y cuyo objetivo es conectar conjuntos de información especializada. Estas conexiones tienen, de hecho, mayor importancia que nuestro estado actual de conocimiento. (George Siemens, 2005, p 10)

Para George Siemens, el conectivismo sobrepasa las teorías del aprendizaje tradicionales (el conductismo, el cognitivismo y el constructivismo) ya que las condiciones de aprendizaje subyacentes han cambiado significativamente con el crecimiento exponencial de la tecnología y la alta velocidad de crecimiento del conocimiento, que es el «talón de Aquiles» que debilita las teorías existentes.

El conectivismo, para sus defensores, supone un estadio superior de los tres modelos anteriores tradicionales (conductismo, cognitivismo y constructivismo), los cuales no consideran el aprendizaje alcanzado fuera de los individuos (o sea, aprendizaje almacenado y manipulado por tecnologías), como tampoco pueden describir cómo ocurre al aprendizaje en colectivo. (Sobrino, 2014, p. 39)

La tesis conectivista sostiene que el aprendizaje se refiere a la adquisición del conocimiento que posteriormente el individuo es capaz de aplicar en una situación determinada, pero parte de este conocimiento puede residir fuera de la memoria del individuo. El conductismo, el cognitivismo y el constructivismo no permiten modelar cómo funciona el proceso de aprendizaje desde esta nueva perspectiva. Además, los cambios en el proceso de aprendizaje también ponen de manifiesto que el individuo debe ser capaz de determinar cuál es el aprendizaje que debe realizar, y por tanto, debe analizar qué valor tiene un determinado aprendizaje. En este sentido, hay que tener en cuenta que los métodos anteriores al conectivismo, no permitían modelar la evaluación de la idoneidad de aprender un determinado conocimiento.

La interacción entre los diferentes componentes del proceso del aprendizaje es una de las bases del conectivismo. El conocimiento está dentro de la red y los alumnos lo buscan cuando necesitan, y por medio de la interacción con los demás construyen nuevas redes que permiten ajustar y reconfigurar el conocimiento anterior. Así, como que el aprendizaje no es una actividad individual, la comunicación con los demás individuos debe permitir establecer un diálogo fluido. Obdulio Martín dice a este propósito:

El conectivismo de Siemens parte de la idea de que el conocimiento se basa en el deseo de aprender, pero a través de interacciones entre personas y dispositivos tecnológicos; del establecimiento de redes y de la actualización permanente de la información. El alumno aprende continuamente por medio de redes y conexiones que establece, aprende en la red y en red. Según esta teoría, el aprendizaje está construido/creado en comunidad y el conocimiento es el resultado de la construcción conjunta de expertos (de maestros) y aprendices. (CARNEIRO, Roberto. TOSCANA, Juan Carlos. DIAZ. 2009, p 81) 
El profesor, al igual que en el constructivismo, no debe ser el transmisor del conocimiento, sino que es quien debe establecer los mecanismos y procedimientos que permitan que el alumno pueda realizar el aprendizaje, debe motivar, guiar y facilitar la participación de los estudiantes en la comunidad. Los métodos pedagógicos deben enseñar al alumno a escoger cuál es el conocimiento que necesita aprender y a saber buscar la información en diferentes fuentes de información y tener un espíritu crítico para descartar las informaciones no fiables. La evaluación del alumno se realizará sobre el proceso en el que configura su red de aprendizaje, sobre cómo selecciona los nodos más adecuados para alcanzar los objetivos iniciales.

Cabe señalar que los diferentes modelos de aprendizaje, el conductismo, el cognitivismo, el constructivismo y el conectivismo, tienen diferentes aplicaciones. Así, en algunas situaciones, los métodos basados en los modelos conductistas son suficientes para realizar el aprendizaje, pero la mayoría de veces el conductismo es insuficiente y hay que utilizar los otros métodos. Aplicar el método adecuado es una de las tareas que debe realizar el pedagogo. En este sentido, las TIC dentro de las aulas deben ser lo más neutros posibles, no deben imponer un método pedagógico concreto, sino que deben poder adaptarse a las decisiones del pedagogo sobre cuál es el método más adecuado en cada momento. Así, las TIC han de ser flexibles, y deben adaptarse a las necesidades pedagógicas.

Las concepciones de la enseñanza, hasta ahora, se han enmarcado en dos grandes tendencias: la tendencia conductista que concibe el aprendizaje como la transmisión de conocimientos del profesor al alumno, y la tendencia cognitiva, en la que se adscriben los paradigmas del cognitivismo y el constructivismo, así como el conectivismo, y que tiene en cuenta las peculiaridades de la estructura interna del individuo en el proceso del aprendizaje.

En cuanto a la universidad marroquí, si tuviéramos que situar las prácticas de los profesores dentro de las teorías del aprendizaje, el conductismo sería el que más se acerca a lo que se hace en las aulas. Sin embargo, la introducción de las TIC necesitaría un cambio importante en estas prácticas de la enseñanza hacia un paradigma que iría seguramente más hacia el constructivismo, puesto que ninguna integración de las TIC podría hacerse sin un enmarque teórico constructivista. Habrá que ver, también, si con el tiempo este cambio se consolida y qué papel jugará la nueva teoría del conectivismo.

\section{Anotaciones finales}

La universidad marroquí, debe emprender algunos cambios para enfrentar la nueva realidad, reubicarse en un escenario globalizado que implica potenciar la interdisciplinariedad, el dominio de lenguas extranjeras, la movilidad de profesores y alumnos. Debe adaptarse a las demandas del empleo y constituir un motor de desarrollo local, tanto en lo cultural como en lo social y económico. La incorporación de las TIC constituye una alternativa que permite a la universidad marroquí situarse en un contexto de gran competitividad donde se exige calidad y capacidad de cambio y mejorar la gestión en un contexto de reducción de recursos públicos. Pero todos estos cambios no se pueden implantar de forma concreta, sino que deben ir apoyados por una reestructuración del sistema universitario en general.

El potencial de las TIC para la enseñanza y el aprendizaje queda, entonces, dependiente de las características de las herramientas que se utilizan y las prácticas de su uso y que podemos resumir en los tres puntos siguientes:

- El diseño tecnológico y las posibilidades genéricas de las herramientas tecnológicas. No todas las 
herramientas ofrecen las mismas posibilidades; cada una, que sean de navegación, de construcción, de redes semánticas, de visualización o de simulación, ofrecen distintas posibilidades para organizar actividades de enseñanza-aprendizaje. Unas son más aptas para organizar unas actividades que otras. Cuando tratamos de incorporar las TIC desde la perspectiva de su uso a los procesos de enseñanza- aprendizaje, tenemos que preguntarnos sobre las características de las herramientas.

- Las herramientas tecnológicas diseñadas para el proceso de enseñanza-aprendizaje siempre se presentan insertas en un diseño tecnológico con objetivos, contenidos, y herramientas y su uso para determinadas actividades.

- Los diseños de actividades de enseñanza basadas en las TIC son una planificación, una programación y su puesta en marcha. Por lo tanto, tiene que ser muy precisa y detallada, ya que la dinámica que se genera en el aula es diferente y sólo teniendo una programación precisa seremos capaces de adaptarnos a los imprevistos sin perder el rumbo.

Entonces, para hacer efectiva esta potencialidad que encierran las TIC para la educación, hemos de unir un esfuerzo considerable en el ámbito de la infraestructura y los equipamientos con un esfuerzo similar en el ámbito de la formación de los profesores en los usos de las TIC; en definitiva, lo que va a transformar y mejorar la enseñanza no son las TIC, sino los usos de estas tecnologías y que forman parte de proyectos pedagógicos y didácticos transformadores.

El mundo digital ha venido para quedarse y la educación ha de generar un aprendizaje soportado en gran medida en estrategias digitales. Los trabajos más demandados hoy no existían antes y no van a existir en el futuro, o por lo menos como los conocemos hoy. Resulta evidente que esta situación va a requerir nuevas competencias que van a requerir a su vez unas respuestas del mundo educativo. Los docentes nos encontramos hoy, más que nunca, ante un dilema: nos formaron en décadas pasadas, que enseñamos a alumnos de esta década y que han de trabajar en décadas futuras. Grandes dilemas que se presentan a la educación en la era digital.

\section{Notas:}

1- http://www.taalimtice.ma/fr/node/225

2- https://www.add.gov.ma/presentation-de-ladd

3- Es un organismo creado en 2001 para mejorar las condiciones estructurales de los agentes del sector educativo.

4- El informe fue publicado en abril 2021 en colaboración con la Agencia de Desarrollo Digital (ADD), recuperado el 10 de junio de 2021 de https://oxfordbusinessgroup.com/ blog/bernardo-bruzzone/focus-reports/report-what-lasting-impact-will-pandemic-havedigitalisation

5- Gráfico adaptado de una encuesta del informe anual (2019) la Agencia Nacional de Reglamentación de Telecomunicaciones (ANRT). http://www.anrt.ma/publications/notesdorientations-generales

6- Es un organismo público responsable del control y la regulación del sector de las telecomunicaciones en Marruecos.

7- Gráfico adaptado de una encuesta del informe anual la Agencia Nacional de Reglamentación de Telecomunicaciones (ANRT). http://www.anrt.ma/publications/notesdorientations-generales

8- Gráfico adaptado de una encuesta del informe anual la Agencia Nacional de 


\section{Reglamentación de Telecomunicaciones (ANRT). http://www.anrt.ma/publications/notes-} dorientations-generales

\section{Bibliografía :}

AUSBEL, David, NOVAK, Joseph; HANESIAN, Helen. (1983) Psicología Educativa. Trillas. México.

BARRETO, C. R., y IRIARTE Diazgranados , F. (2017). Las Tics en la educacion superior: Experiencias de innovacion. Barranquilla: Universidad del Norte.

BENKARAACH, T., BENABDELOUAHED R., BELAFHAILI M., DAFIR A., NEFZAOUI A., EL MARHOUM A. (2020) «Continuité pédagogique et enseignement à distance en période de confinement: Perception et satisfaction des acteurs», Enquête nationale auprès des étudiants et des enseignants, L'économiste $n^{\circ} 5770$ du jeudi 20 mai 2020.

CABERO, Julio. (2001). Tecnología educativa. Diseño y utilización de medios en la enseñanza. Paidós. Barcelona.

CARNEIRO, Rberto. TOSCANA, Juan Carlos. DIAZ, Tamara (Coordinadores). (2009) Los desafíos de las TIC para el cambio educativo, Madrid, Fundación Santillana. Madrid

CERDA, Cristian. (2002). Elementos a considerar para integrar las tecnologías del aprendizaje de manera eficiente en el proceso de enseñanza aprendizaje. Estudios pedagógicos. (pp.179-191). Disponible en: http://redalyc.uaemex.mx/src/inicio/ArtPdfRed.jsp?iCve=173513847011.

ERTMER, Peggy. NEWBY, Timothy (1993). Conductismo, Cognitivismo y Constructivismo: Una comparación de los aspectos críticos desde la perspectiva del diseño de instrucción. Performance Improvement Quarterly. Disponible en:

http://crisiseducativa.files.wordpress.com/2008/03/conductismo cognitivismo constructivismo.pdf

FOULQUIÉ, Paul. (1976). Diccionario de Pedagogía. Oikos-tau. Barcelona

GUTIERREZ MARTIN, Alfonso. (2007) Integración curricular de las TIC y educación para los medios en la sociedad del conocimiento. Revista Iberoamericana de Educación. Disponible en: http:// www.rieoei.org/rie45a06.htm.

MARTÍN, G., MARTíNEZ, R., MARTÍN, M., NIETO, M. y NÚÑEZ, S. (2017). Acercamiento a las teorías del aprendizaje en la educación superior. UNIANDES EPISTEME, 4(1), 48-60.

PISCTELLI, Alejandro. (2006) Nativos e inmigrantes digitales: ¿brecha generacional, brecha cognitiva, o las dos juntas y más aún? Revista mexicana de Investigación Educativa,. vol.11, número 028. Disponible en http://fr.scribd.com/doc/467656/Nativos-e-Inmigrantes-Digitales.

SALVAT, Begoña Gros. (2000). El ordenador invisible. Hacia la apropiación del ordenador en la enseñanza, EdiUOC, Barcelona.

SIEMENS, George. (2005). Conectivismo: Una teoría de la enseñanza para la era digital. International Journal of Instructional Technology and Distance Learning 2.

SOBRINO MORRÁS, Ángel. (2014). Aportaciones del conectivismo como modelo pedagógico postconstructivista Propuesta Educativa, núm. 42, pp. 39-48 Facultad Latinoamericana de Ciencias Sociales Buenos Aires, Argentina.

TORRENTERAS, J. (2015). Las teorías de aprendizaje y la formación de herramientas técnicas. Revista de Educación a Distancia, 34, 25-31.

VYGOTSKY, Lev Semiónovich. (1981) Pensamiento y lenguaje. La Pléyade. Buenos Aires. 